\title{
EDITORIAL
}

\section{FEV6: a shortcut in spirometry?}

\author{
O.F. Pedersen
}

D uring the past 50 yrs, the forced expiratory manoeuvre has formed the basis for the most extensively used lung function test. Although "spirometry" means measurement of breath and, therefore, should include all kinds of measurements related to breathing, it is now almost a convention that spirometry is synonymous with measurements involving a forced vital capacity (FVC).

In his historical note, YERNAULT [1] mentions that Tiffenau and Pinelli published the first results from recording forced expiration manoeuvres in 1947. A couple of years later, the Tiffeneau test was developed, defining the ratio between the forced expiratory volume in one second (FEV1) and the vital capacity (VC). To calculate this ratio, both the FVC and the VC (always measured during expiration) became acceptable. With spirometry, there is a potential ability to diagnose obstructive and restrictive abnormalities. Obstruction is a condition with decreased FEV1/VC, whereas restriction is a condition with decreased total lung capacity (TLC). Therefore, it is important that the VC (or FVC) gives the best possible measure of TLC. A decreased VC may occur due to loss of alveolar space, which decreases TLC. Obstruction may lead to airway closure and a decrease of FVC, but TLC is not decreased. The largest VC is the inspiratory vital capacity (IVC), which is measured during a slow inspiration from residual volume to TLC, and, therefore, IVC was recommended as the denominator in the FEV1/ VC ratio [2]. As IVC cannot be obtained during the FVC manoeuvre, it requires an extra measurement, and is seldom used outside specialised lung function laboratories. The use of FVC instead is not without problems. In severely obstructed patients, the total exhalation may last for up to $20 \mathrm{~s}$ [3], until the current end-of-test standards for accurately measured FVC [4] are met. This may be very demanding for both the patient and the technician. Furthermore, very few spirometers have feedback systems that indicate when these criteria are met.

In 1987, GLINDMEYER et al. [5] therefore suggested an end-of-test criterion based on a fixed duration for the FVC manoeuvre. It was found that $6.64 \mathrm{~s}$ was sufficient to obtain $99 \%$ of FVC for spirograms with FEV1/FVC as low as $50 \%$. As a consequence, HANKINSON et al. [6] calculated FEV6 and FEV1/FEV6 reference equations and their lower limits of normal (LLN) based on 74,294 healthy subjects in the National Health and Nutrition Examination Survey III study. In a similar European study [7] of males and females aged 65-80 yrs old, the basis has been formed for comparisons of predictions of obstructive and restrictive lung disorders by using FEV6 and FVC.

CORRESPONDENCE: O.F. Pedersen, Institute of Public Health, Dept of Environmental and Occupational Medicine, Building 260, University of Aarhus, Venneyst Blv 6, DK-8000 Aarhus C, Denmark. Fax: 45 89426199. E-mail: OFP@MIL.AU.DK
In this issue of the European Respiratory Journal (ERJ), there are two papers on this subject $[8,9]$. Using Hankinson's prediction equations, AKPINAR-ELCI et al. [8] examined 1,139 workers in the workplace, and defined airways obstruction as FEV1/FVC $<$ LLN and restriction as normal FEV1/FVC and FVC $<$ LLN. They found that, by replacing FVC with FEV6 and using the proper reference equations, the sensitivity of the FEV6 method was 0.94 , which means that if a subject is confirmed as being ill by the FVC method (the gold standard), then there would be a $94 \%$ probability that he/she would also be confirmed as being ill by the FEV6 method. This means that $6 \%$ of the subjects would be classified as healthy, despite being ill. There is, however, also a possibility that, when tested as healthy by the FVC method, the subjects may have obstruction or restriction when tested by the FEV6 method, but the risk of being classified as ill was only $2 \%$, since the specificity of the test was 0.98. SWANNEY et al. [3] studied 337 patients in the same manner, and VANDEVOORDE et al. [10] recently published a study of 11,676 subjects examined in a lung function laboratory. For detection of abnormal spirometry, both papers found sensitivities and specificities of the same overall magnitude, as in the study by AKPINAR-ELCI et al. [8]. In all three studies, the FEV6 test showed slightly lower sensitivity (mean 0.88 ) in the detection of restrictive than obstructive disorders (mean 0.94).

The other paper presented in this issue of the ERJ by VANDEVOORDE et al. [9] calculates which values of FEV1/FEV6 and FEV6 will best match an FEV1/FVC of 0.70 and FVC $80 \%$ of predicted. This is of interest because of the widely used Global Initiative for Chronic Obstructive Lung Disease (GOLD) criteria [11] that classify mild chronic obstructive pulmonary disease by FVC $>80 \%$ of predicted and FEV1/FVC $<70 \%$. VANDEVOORDE et al. [9] found the best match to be an FEV1/ FEV6 of 0.73 and FEV6 of 0.82 . They warn that fixed cut-offs should be used with caution, since spirometric indices are highly influenced by age, height, sex and race. With this in mind, they found FEV1/FEV6 and FEV6 suitable for screening purposes in primary care.

An analysis of discordant cases was performed by both AKPINAR-ELCI et al. [8] and VANDEVOORDE et al. [9]. The former found 43 cases $(3.8 \%)$ and the latter 842 cases $(7.2 \%)$. All of them had values close to the LLN. As highlighted by SWANNEY et al. [3], who found 14 discordant cases (4.1\%), the reason for discordance can be between-test variability, and, therefore, would also occur if the subjects had been tested twice with the same method. As pointed out by most authors, there will always be uncertainties when values are near the LLN. This is true for both FVC and FEV6 and is illustrated in figure 1 of the study by APKINAR-ELCI et al. [8], with the discordant 
measurements in the first and third quadrants. The points of the whole population seem to be scattered around the line of identity, indicating that there is no systematic difference between the methods. One could argue that, in case of increasing severity of obstruction, FEV6 is expected to be increasingly smaller than FVC [8]. This is apparently not so. Maybe this is adequately taken care of by the reference equations, even though they are based only on healthy subjects [6]. The subjects in the study were active workers, and none of them could be expected to be seriously ill.

If the proper reference equations are not used, there will be an underestimation of obstruction, as found by DEMIR et al. [12]. In their study of 5,114 patients, they found that among those with FEV1/FVC $<0.70$, only $86 \%$ also had FEV1/FEV6 $<0.70$. This can only be due to the fact that FEV6 underestimates FVC. Actually, they found four patients where FVC exceeded FEV6 by $>1 \mathrm{~L}$. The difference between FEV1/FEV $6 \%$ and FEV1/ FVC $\%$ increases from about 4 to 9 when $\mathrm{FEV} 1 / \mathrm{FVC} \%$ decreases from 70 to 50 [13]. If this difference is taken into account using the appropriate reference equations, the FEV1/ FEV6 seems to be as good as FEV1/FVC in the prediction of obstruction and restriction.

To get the best prediction of TLC, it seems important that the procedure used for obtaining VC gives the largest possible value. GLADY et al. [14], who measured TLC found, however, that there was no difference between FVC and a slow VC in the prediction of restriction. Based on their analysis, other cut-off points were chosen: FEV1/FVC $>55 \%$ and FVC $<85 \%$ predicted, instead of using the American Thoracic Society (ATS) criteria. This diminished the number of patients requiring TLC measurements for validation of restriction. SWANNEY et al. [15], who also measured TLC, included FEV1/ FEV6 and FEV6 in their similar analysis. They found that applying FVC instead of FEV6 did not improve the prediction of restriction. Furthermore, TLC was only reduced in 55 and $57 \%$, respectively, of the cases where spirometry indicated restriction. A similar figure was found by AARON et al. [16], who found that, for FVC $<60 \%$ of the predicted value, the probability of a restrictive defect decreased when FEV1/FVC decreased.

As obstruction is defined as FEV1/FVC < LLN, spirometry directly defines obstruction depending on the reference equations used. FEV1/FEV6 shows obstruction in only $\sim 95 \%$ of the cases, since FEV6 relatively underestimates FVC. Therefore, the use of FEV6 instead may slightly change the definition of obstruction. However, restriction is another matter. When FVC is within the normal range, the probability of a restrictive lung disease (TLC $<$ LLN) is $<3 \%$ as shown in studies where TLC was measured $[15,16]$, but, when FVC $<\mathrm{LLN}$, spirometry is not able to satisfactorily predict restriction. This means that determination of TLC is necessary for patients with only spirometric evidence of restriction. Algorithms can be made with cut-off points that optimise the sensitivity and specificity of spirometry and minimise the demand for further examination. The use of these algorithms becomes a political and economic issue. All patients deserve a correct diagnosis to ensure a correct treatment. Therefore, the algorithm recommended by the ATS/European Respiratory Society Task Force [17] should be used, and determination of
TLC should be carried out accordingly. The algorithm can be used with FEV6, as well as with FVC. Special care should be taken with interpretation of values near the LLN, where misclassification is most likely to occur. More research is needed in this area.

Five years ago, a consensus statement from the National Lung Health Education Program [18] went so far as to state "office spirometers must only report values for FEV1, FEV6, and FEV1/FEV6", but, if the spirometer does not have the facility to calculate FEV6, one could still use FVC. Obviously, FEV6 is here to stay. It seems to be a promising shortcut in spirometry, providing the proper reference equations are used. As mentioned previously, the equations by HANKINSON et al. [6] include FEV6, and they are recommended for use in the USA [17]. In Europe, the equations of GARCIA-RIO et al. [7] cannot be applied generally, as they are only valid for a limited age range. Currently, no specific set of equations is recommended for use in Europe, and there is a need for a new Europe-wide study to derive updated reference equations for lung function [17], which should include FEV6.

In conclusion, the bottom line is that, for prediction of obstruction, it does not apparently matter much whether slow vital capacity, forced vital capacity or forced expiratory volume in six seconds are used. For prediction of restriction, they are equally poor.

\section{REFERENCES}

1 Yernault JC. The birth and development of the forced expiratory manoeuvre: a tribute to Robert Tiffenau (19101961). Eur Respir J 1997; 10: 2704-2710.

2 Quanjer PhH, Tammeling GJ, Cotes JE, et al. Standardized lung function testing: lung volumes and forced ventilatory flows. Eur Respir J 1993; 6: Suppl. 16, 5s-40s.

3 Swanney MP, Jensen RL, Crichton DA, Beckert LE, Cardno LA, Crapo RL. FEV6 is an acceptable surrogate for FVC in the spirometric diagnosis of airway obstruction and restriction. Am J Respir Crit Care Med 2000; 162: 917-919.

4 Miller MR, Hankinson J, Brusasco V, et al. Standardisation of spirometry. Eur Respir J 2005; 26: 319-338.

5 Glindmeyer HW, Jones RN, Barkman HW, Weill H. Spirometry: quantitative test criteria and test acceptability. Am Rev Respir Dis 1987; 136: 449-452.

6 Hankinson JL, Odencrantz JR, Fedan KB. Spirometric reference values from a sample of the U.S. general population. Am J Respir Crit Care Med 1999; 159: 179-187.

7 Garcia-Rio F, Pino JM, Dorgham A, Alonso A, Villamor J. Spirometric reference equations for European females and males aged 65-85 yrs. Eur Respir J 2004; 24: 397-405.

8 Akpinar-Elci M, Fedan KB, Enright PL. FEV6 as a surrogate for FVC in detecting airways obstruction and restriction in workplace. Eur Respir J 2006; 27: 374-377.

9 Vandevoorde J, Verbanck S, Schuermans D, Kartounian J, Vincken W. Obstructive and restrictive spirometric patterns: fixed cut-offs for FEV1/FEV6 and FEV6. Eur Respir J 2006; 27: 378-383.

10 Vandevoorde J, Verbanck S, Schuermans D, Kartounian J, Vincken W. FEV1/FEV6 and FEV6 as alternative for FEV1/ FVC and FVC in the spirometric detection of airway obstruction and restriction. Chest 2005; 127: 1560-1564. 
11 NHLBI/WHO workshop 1998. Global initiative for chronic obstructive lung disease. Global strategy for the diagnosis, management, and prevention of chronic obstructive pulmonary disease. www.goldcopd.org/Guidelineitem. asp? $11=2 \& 12=1 \&$ intId $=989$. Date last updated: September 2005. Date last accessed: November 24, 2005.

12 Demir T, Ikitimur HD, Koc N, Yildirim N. The role of FEV6 in detection of airway obstruction. Respir Med 2005; 99: 103-106.

13 Enright PL, Connett JE, Bailey WC. The FEV1/FEV6 predicts lung function decline in adult smokers. Respir Med 2002; 96: 444-449.

14 Glady CA, Aaron SD, Lunau M, Clinch J, Dales RE. A spirometry based algorithm to direct lung function testing in the pulmonary function laboratory. Chest 2003; 123: 1939-1946.
15 Swanney MP, Beckert LE, Frampton CM, Wallace LA, Jensen RL, Crapo RO. Validity of the American Thoracic Society and other spirometric algorithms using FVC and forced expiratory volume at $6 \mathrm{~s}$ for predicting a reduced total lung capacity. Chest 2004; 126: 1861-1866.

16 Aaron SD, Dales RE, Cardinal P. How accurate is spirometry at predicting restrictive pulmonary impairment? Chest 1999; 115: 869-873.

17 Pellegrino R, Viegi G, Brusasco V, et al. Interpretative strategies for lung function tests. Eur Respir J 2005; 26: 948-968.

18 Ferguson GT, Enright PL, Buist S, Higgins MW. Office spirometry for lung health in adults. A consensus statement from the National Lung Health Education Program. Chest 2000; 117: 1146-1161. 